\title{
The Effects of Recognition and Group Need on Volunteerism: A Social Norm Perspective
}

\author{
ROBERT J. FISHER \\ DAVID ACKERMAN *
}

\begin{abstract}
The significance of volunteering for both individuals and society has lead to numerous studies on this behavior across the social sciences. However, virtually no prior research has evaluated how and to what extent organizations can effectively encourage individuals to contribute time to a worthy cause. The present research uses a social norm perspective to examine the conditions under which promotional appeals based on group need and promises of recognition affect volunteerism. The perspective suggests that norm compliance can be expected only when the prescribed behavior is both important to the group's welfare and subject to group-mediated rewards. Consequently, we hypothesize that promotional appeals based on group need and promised recognition are effective only when they are used in combination. Results of a laboratory and a field experiment are consistent with this hypothesis and provide insights into the process by which the appeals affect individuals' decisions to help. The results also have implications for understanding and promoting other socially desirable behaviors such as recycling, energy conservation, litter reduction, and the purchase of "green" products.
\end{abstract}

$\mathrm{T}$ he decision to volunteer is an important, life-altering commitment for many individuals. Of the estimated 94 million American adults engaged in some form of volunteerism, 25 million donate five or more hours per week (Independent Sector 1992). Given that the average American adult spends approximately 17 hours per week in leisure (Samuelson 1989), volunteering often represents a significant proportion of total nonworking time. Moreover, volunteering affects expenditures of one of the scarcest and therefore most precious commodities: discretionary time (Hawes 1977; Holbrook and Lehmann 1981). Volunteering means fewer hours on the golf course, at the movies, or in the pursuit of other recreational or consumption activities. It also means less time devoted to wealth creation either in the form of career advancement or part-time sources of income.

From a more macro perspective, volunteer work can be viewed as a nonmarket activity that provides services that otherwise would not be available in a community

\footnotetext{
${ }^{*}$ Robert J. Fisher is associate professor of marketing at the Richard Ivey School of Business, University of Western Ontario, London, Ontario, N6A 3K7. David Ackerman is a doctoral candidate at the Marshall School of Business Administration, University of Southern California, Los Angeles, CA, 90089-1421. The authors would like to thank members of the 1996 UCI/UCLA/USC Marketing Colloquium, Valerie Folkes, Gerry Tellis, Melanie Wallendorf, the editors, and three reviewers for their thoughtful comments and suggestions. They would also like to thank American Youth Soccer Organization Region 23 for allowing them access to the subjects used in experiment 2.
}

(Schram and Dunsing 1981). Volunteers make possible programs for children such as little league and scouts, extracurricular activities at public schools, and act as a substitute for government-support programs for the disadvantaged. Without volunteer participation the services that are offered by many profit and nonprofit organizations would be unavailable or provided at higher cost to consumers and taxpayers. Consider that volunteers are an inexpensive or free labor source for some 40,000 organizations in the United States (Kotler 1982) and generate services worth more than $\$ 150$ billion annually (Independent Sector 1992).

The importance of volunteerism to both individuals and society has lead to numerous studies on volunteer motivations across the social sciences. Research can be found in social psychology (e.g., Harrison 1995; Omoto and Snyder 1995); sociology (e.g., Babchuk and Gordon 1962); organizational behavior (e.g., Pearce 1993); leisure research (e.g., Henderson 1981); social issues (e.g., Jenner 1981); voluntary organizations (e.g., Bonjean, Markham, and Macken 1994; Gallup Organization 1987); and economic psychology (e.g., Unger 1991). ${ }^{1}$ Despite

\footnotetext{
${ }^{1}$ Numerous studies in social psychology have investigated helping behaviors in general. The typical experiment constructs a situation in which one individual has the opportunity to provide aid to a stranger on a one-time basis while manipulating factors such as the mood of the prospective helper, the ease of helping, or the potential to escape the situation. The focus has been on the degree to which helping is motivated by empathy-based altruism (e.g., Batson 1990; Carlo et al. 1991) or
} 
the wide breadth of studies on the topic, prior research sheds little light on how organizations can encourage volunteerism because studies in the area typically use crosssectional designs and sample only those who volunteered. The reliance on self-report methods also makes the data vulnerable to social desirability bias (Fisher 1993). Given that helping others for personal gain is contrary to social norms, self-reports are likely to overestimate altruistic reasons for volunteering and underreport instrumental ones such as personal development, career advancement, and social approval (Smith 1981).

Research in consumer behavior and marketing provides limited guidance on volunteerism, despite a variety of studies on other types of giving. Prior research has examined the effects of attitudes on blood and body-part donations (Bagozzi 1981, 1982; Burnett 1981; Burnkrant and Page 1982; LaTour and Manrai 1989; Pessemier, Bemmaor, and Hanssens 1977), the effectiveness of fundraising promotional strategies (e.g., Bagozzi and Moore 1994; Meyers-Levy and Maheswaran 1992), and compliance techniques such as a-foot-in-the-door and even-apenny-will-help (e.g., Fraser, Hite, and Sauer 1988; Moore, Bearden, and Teel 1985; Reingen 1978). A recent literature review by Bendapudi, Singh, and Bendapudi (1996) reveals only one study in marketing and consumer behavior that examines volunteerism, and this study focuses primarily on financial contributions (i.e., Dawson 1988).

Accordingly, there is limited knowledge of how and to what extent organizations can promote volunteerism. The present research uses norm theory to investigate this substantive issue because volunteering is a socially desirable, and therefore normative, behavior. Norm theory asserts that norms are most effective in regulating behaviors that are both important to the group's welfare and backed by socially mediated rewards or punishments (Schwartz 1977). We therefore hypothesize that volunteerism is increased only when promotional appeals emphasize both the group's need and promise recognition to those who help. Unlike prior survey-based studies, we use a between-subjects experimental design that improves our ability to make causal inferences and reduces the potential for social desirability bias.

We begin the article with a discussion of the literature that was used as a framework for the research. Next, we present the designs and results of two studies. The first study is a laboratory experiment in which students are asked to volunteer for a school fund-raising team. The second study is a field experiment based on a sample of parents who are registering their children for a youth sports league. Finally, we discuss the implications of the research for understanding and promoting volunteerism and other socially desirable behaviors.

more instrumental concerns such as the avoidance of stress or sadness (e.g., Baumann, Cialdini and Kendrick 1981; Cialdini et al. 1987).

\section{A NORMATIVE PERSPECTIVE ON VOLUNTEERING}

One way that groups regulate the conduct of their members is through the establishment and reinforcement of norms. We define norms as perceptions, attitudes, and behaviors that are approved of by the group and expected of its members (cf. Baron, Kerr, and Miller 1992). Norms specify what is socially sanctioned, that is, what group members should or ought to do in a particular situation (Cialdini, Kallgren, and Reno 1991). Norms are not usually written down or discussed openly, but they have a strong influence on a wide range of behaviors (Feldman 1984; Leary 1995).

Norms are reinforced within groups through socially mediated rewards and punishments (DeRidder, Schruijer, and Tripathi 1992). Individuals who comply with norms can expect to create a good impression or receive praise for their actions, whereas those who do not can anticipate negative verbal or visual expressions of disappointment, or even outright rejection (Festinger, Schachter, and Back 1950). Expectations of rewards (and the avoidance of sanctions) have been found to motivate a variety of socially desirable behaviors including helping those in need (Bandura 1977; Baumann et al. 1981; Berkowitz and Daniels 1964; Eisenberg 1982), reciprocity (Gouldner 1960), and pro-environmental actions (Reno, Cialdini, and Kallgren 1993).

Norms vary greatly in importance and therefore so does the extent to which behavioral compliance is required by the group (DeRidder et al. 1992). Whereas weak norms allow for a wide latitude of behaviors, strong norms demand more precise responses. In general, the most important norms regulate behaviors that affect the group's survival and prosperity. As a consequence, the more important a behavior is to the group, the stronger the expectation that group members will undertake it. We examine the relationship between the importance of helping and the willingness to volunteer in the next section.

\section{Group Need and the Importance of Helping}

Anecdotal evidence abounds of attempts by charitable and other nonprofit organizations to motivate volunteering and other helping behaviors by emphasizing the significance of their need. For example, a 1996 letter requesting financial contributions for a local PBS station refers to cuts in federal funding and states, "We just can't make it without Member support.' The appeal highlights the dire situation facing the organization and the significance of the member's help. Also, the level of need can be represented by the success of the organization in achieving its goals. The United Way, for example, establishes specific financial targets for each community and corporate campaign. The degree to which the organization's fund-raising objective is attained is a direct measure of the campaign's success and hence the need for further financial and volunteer support. 
Because group members are expected to assist their group in achieving its collective purpose (Tajfel 1970), groups invoke this norm when they promote the significance of their need. When group need is high, group members are expected to volunteer because they have the opportunity to make an important contribution. Without their support the group would be unable to accomplish its charitable goals. Volunteering is less critical when the group is self-sufficient, and so the expectation that group members will volunteer should be weak.

Nevertheless, norms are unlikely to guide even the most important behaviors unless social consequences are expected for compliance or deviance (e.g., Reno et al. 1993 ). Although group members should feel an obligation to help when group need is high, a social norm perspective suggests that they will act only if the behavior is monitored and rewarded (Schwartz 1977). Recognition provides one mechanism for elevating the visibility of desired behaviors and creating favorable social consequences for the recipient. We discuss these effects in a volunteering context in the next section.

\section{The Promise of Recognition}

Recognition is a strategy that is frequently used by charitable and nonprofit organizations. For example, the American Red Cross, American Legion, YMCA, and United Way use dinners and special events to recognize the contributions of those who help (American Red Cross 1988; Brakeley 1980; Leibert and Sheldon 1972; McGee 1988; Unger 1991). Formal recognition ceremonies and other noneconomic rewards provide an important basis for volunteer recruitment and motivation because, by definition, volunteers are not compensated monetarily for their efforts and are free to withdraw their support from the organization at any time.

We define recognition as a public expression of appreciation given by a group to individuals who undertake desired behaviors. Although recognition can include elements that have economic value such as cash awards or prizes, these aspects are neither necessary nor sufficient. Indeed, recognition symbols such as plaques, certificates, and trophies have no commercial value once they have been personalized to include the recipient's name, organization, and charity event (unless, perhaps, the recipient is famous). Who would want to purchase a plaque that honors someone else's volunteering contribution to Meals on Wheels? At the same time, personalizing a recognition object increases its symbolic value to the recipient because it incorporates meanings that were absent in the original commodity (e.g., an "off-the-shelf", trophy or plaque). Recognition is therefore distinct from commissions, bonuses, or incentives that are effective because of their monetary value.

Recognition differs from informal and private forms of appreciation such as a manager congratulating a volunteer on a "job well done" in a hallway conversation. In this situation the only two individuals who have direct knowl- edge of the interaction are the manager and worker, and so the rewards created by the act are primarily personal (e.g., feelings of satisfaction and competence). ${ }^{2}$ In contrast, recognition publicly communicates the group's respect for those who support the group, and thereby raises the recipient's status and prestige (cf. Belk 1995; Turner 1988 ). For example, a volunteer who works behind the scenes in a clerical or secretarial capacity might be relatively anonymous until recognition makes his or her contribution visible. The individual's fellow group members or other referents then have the opportunity to express their appreciation for and admiration of the volunteer.

Despite the apparent power of recognition to generate favorable social consequences for the recipient, its impact cannot be determined independently of the rewarded behavior. When recognition is promised under low groupneed conditions, volunteers anticipate a public display of appreciation for conduct that is not strongly prescribed by group norms. The social consequences of volunteering should not be enhanced because the value of recognition depends on the importance of the rewarded behavior. We therefore hypothesize that volunteerism is not increased when recognition is promised under low group-need conditions. In contrast, we expect that volunteerism is elevated when the behavior is important and recognition is promised. In this situation, group members believe that their help is critical to the group and that others will be made aware of their contribution. The social consequences are significant because the behavior is both highly desirable and visible.

\section{EXPERIMENT 1}

Experiment 1 was conducted in a competitive group context. We reasoned that in this situation, group success would have a significant negative effect on evaluations of group need. If the organization is not likely to achieve its competitive objective, group members should perceive that the situation is undesirable and their help is needed. Conversely, group members should deduce that the need for additional volunteer help is low if the organization is already successful. We therefore expect that volunteering will be highest under low group success (i.e., high group need) and promised recognition conditions.

As a result, we used a 2 (low/high group success $) \times 2$ (no/promised recognition) between-subjects design to test the hypothesis. We randomly assigned 140 male and female undergraduate students from a required introductory business class to the experimental conditions (3436 per cell). Subjects were contacted within a normal classroom situation. After being introduced to a test administrator "working with the alumni development of-

\footnotetext{
${ }^{2}$ Nevertheless, all face-to-face expressions of appreciation have social implications to the extent that at least two people are involved. Also, even confidential conversations can become public through word of mouth.
} 
fice,' subjects were asked to evaluate the effectiveness of a poster designed to encourage students to volunteer for a fund-raising drive. The realism of the context was such that many subjects approached the administrator on completion of the experiment to inquire about volunteering. Subjects were debriefed as to the true nature of the study in a subsequent class.

The manipulations were contained in a mock-up of a poster included in the experimental package. Group success was manipulated by varying information subjects received about the past performance of business school volunteers in a fund-raising competition called the "Charity Challenge.' The Charity Challenge was described as a yearly competition between top business schools in the area to see which school could raise the most money for charity. In the high success condition the poster headline was 'What's Right about This Picture?', with a picture of a "thumbs up" next to the name of the subject's university and a "thumbs down" next to the names of three rival schools. The poster explained that the subject's business school had won the competition for the past three years. In the low success condition the headline read "What's Wrong with This Picture?', with the "thumbs up" and "thumbs down" pictures next to the rival schools and the subject's school, respectively. The poster explained that the subject's school had lost the fundraising event in each of the past three years.

The recognition manipulation was achieved with information in the poster's text. In the promised recognition condition the poster indicated that the business school was planning to give volunteers a "thank you" plaque at their graduation ceremony. In the no-recognition condition, no information was provided about any formal acknowledgement for volunteer participation. We strengthened the manipulation by including an insert in the promised recognition condition questionnaires that indicated that the type of plaque volunteers received would depend on the number of hours they donated to the fundraising event: bronze (one to five hours), silver ( six to 10 hours ), gold ( $11-15$ hours ), diamond (16-20 hours ), and Dean's Club (21-25 hours).

\section{Measurement}

Manipulation Checks. The recognition manipulation check was measured as the sum of four items reflecting subjects' perceptions about the degree to which volunteers were visibly rewarded for their efforts. Items such as "fund-raising volunteers receive special recognition for helping out'" and 'the business school shows its appreciation to those who volunteer'" were included. The recognition manipulation check was measured on a seven-point "strongly disagree", to "strongly agree", scale $(\bar{X}=$ 13.73, $\sigma=5.55, \alpha=.90$ ). The manipulation of group success was evaluated with a measure of the past performance of the fund-raising group. We used a single-item, seven-point semantic differential scale that asked subjects to describe the Charity Challenge team as either a winner (7) or a loser $(1 ; \bar{X}=4.44, \sigma=1.49)$.

Perceived Group Need. We anticipated an inverse relationship between the success of a competitive group such as the Charity Challenge team and subjects' perceptions of group need. Losing the fund-raising competition for the past three years underlines the school's need for more volunteers whereas winning suggests that additional volunteers are unnecessary. Perceived group need was measured as the sum of four items including "the Charity Challenge team really needs my help" and "it would be important to the success of the Charity Challenge that I help.' The items used a seven-point "strongly disagree", to "strongly agree"' scale $(\bar{X}=14.32, \sigma=4.87, \alpha=.86)$.

Expectations of Social Approval. Based on a normative perspective, we should find a pattern of effects for expectations of social approval that is comparable to that hypothesized for volunteerism. Specifically, expectations of social approval should be elevated only in the low success/promised recognition condition. Further, a social norm perspective asserts that group members undertake expected behaviors because they anticipate positive social consequences, and so we hypothesize that social approval mediates between the group success by promised recognition interaction and volunteerism.

Operationally, we asked subjects the question, "If you volunteered for the fund-raising drive, would people in each of the following groups approve or disapprove of your decision?' Given that the fund-raising group's success is most visible and salient to referents who are directly associated with the school, we asked subjects to predict how other business students, friends at the university, faculty, and fellow volunteers would react if they volunteered. We summed responses to the four items on a nine-point "strongly disapprove"' to "strongly approve", scale $(\bar{X}=26.7, \sigma=5.95, \alpha=.81)$.

Number of Hours Donated. The measure of the number of hours donated was, "If asked, how many hours would you be willing to donate to the fund-raising drive next week? (Fill in the blanks).', Subjects indicated the number of hours they would donate for each day of the week and provided a total of up to 25 hours at the bottom of the column $(\bar{X}=4.48, \sigma=7.73)$.

\section{Results}

Manipulation Checks. An ANOVA of the manipulations and manipulation checks reveals that perceptions of group success and promised recognition were affected as intended. The success manipulation had a significant effect on perceived success $(F(1,139)=34.65, p<.001$, $\left.\bar{X}_{\text {high success }}=5.12>\bar{X}_{\text {low success }}=3.79, \eta^{2}=.45\right)$, and the recognition manipulation had a significant effect on perceived recognition $\left(F(1,139)=30.82, p<.001, \bar{X}_{\mathrm{p}}\right.$ $\left.{ }_{\text {recog }}=16.12>\bar{X}_{\text {no recog }}=11.35, \eta^{2}=.43\right)$. No other significant main or interaction effects were found. 
TABLE 1

INTERACTION EFFECTS OF PROMISED RECOGNITION AND GROUP SUCCESS ON SOCIAL APPROVAL AND VOLUNTEER PARTICIPATION: EXPERIMENT 1

\begin{tabular}{|c|c|c|c|c|}
\hline & \multicolumn{2}{|c|}{ Low group success } & \multicolumn{2}{|c|}{ High group success } \\
\hline & No recognition & $\begin{array}{l}\text { Promised } \\
\text { recognition }\end{array}$ & No recognition & $\begin{array}{l}\text { Promised } \\
\text { recognition }\end{array}$ \\
\hline Social approval & $\begin{array}{c}26.58 \\
(6.24)\end{array}$ & $\begin{array}{c}29.18 \\
(5.46)\end{array}$ & $\begin{array}{c}27.00 \\
(6.76)\end{array}$ & $\begin{array}{c}24.62 \\
(4.76)\end{array}$ \\
\hline Number of hours donated ${ }^{a}$ & $\begin{array}{c}1.21 \\
(1.23)\end{array}$ & $\begin{array}{c}2.35 \\
(1.74)\end{array}$ & $\begin{array}{c}1.38 \\
(1.30)\end{array}$ & $\begin{array}{c}1.06 \\
(1.30)\end{array}$ \\
\hline $\begin{array}{l}\text { Proportion of subjects volunteering } \\
\text { at least one hour } \\
n\end{array}$ & $\begin{array}{l}53 \% \\
36\end{array}$ & $\begin{array}{l}81 \% \\
36\end{array}$ & $\begin{array}{l}59 \% \\
34\end{array}$ & $\begin{array}{l}44 \% \\
34\end{array}$ \\
\hline
\end{tabular}

NOTE. - Values shown are means; standard deviations are in parentheses.

${ }^{\text {a }}$ The square root of the number of hours donated is reported.

Perceived Group Need. As expected there was a main effect of group success on perceptions of the fund-raising team's need of volunteer support $(F(1,139)=6.50, p$ $<.05)$. Examination of the means across the high and low success conditions indicates subjects perceived that the group required more volunteer support when the group was unsuccessful $\left(\bar{X}_{\text {low success }}=15.4>\bar{X}_{\text {high success }}=13.2\right.$, $\left.\eta^{2}=.22\right)$. There was no significant effect of promised recognition on group need $(p>.40)$.

Expectations of Social Approval. We found a significant interaction of promised recognition and group success on social approval $(F(1,139)=6.68, p<.05)$ with the pattern of means consistent with the social norm perspective. We then conducted a series of simple effects tests using $p<.025$ to avoid type I error inflation (see Maxwell and Delaney 1990). These tests reveal that expectations of social approval were significantly higher when recognition was promised under low group success $\left(F(1,71)=5.49, p<.025, \bar{X}_{\mathrm{p} \mathrm{recog}}=29.18>\bar{X}_{\text {no recog }}\right.$ $\left.=26.58, \eta^{2}=.25\right)$ Also, there was no significant effect of promised recognition when group success was high $\left(F(1,67)=2.83 . p>.05, \bar{X}_{\mathrm{p} \text { recog }}=24.62, \bar{X}_{\text {no recog }}\right.$ $\left.=27.00, \eta^{2}=.20\right)$, and no significant difference between the high and low success conditions in the absence of recognition $\left(F(1,69)<1, p>.60 ; \bar{X}_{\text {low success }}=26.58\right.$, $\left.\bar{X}_{\text {high success }}=27.00, \eta^{2}=.05\right)$. The effects of group success and recognition on social approval are consistent with a social norm explanation with a positive effect of promised recognition only in the absence of group success.

Number of Hours Donated. Before we analyzed the effects of group success and recognition on the number of hours donated to the fund-raising group, we examined the distribution of the dependent variable and found that it was highly skewed. The sensitivity of ANOVA results to nonnormal distributions lead us to use the square root of the dependent variable in the hypothesis tests (Wilcox 1993 ). The skew of the dependent variable was reduced from 6.99 to .97 by the transformation.
We found a significant interaction between promised recognition and group success $(F(1,139)=9.26, p<$ $.01)$. Simple effects tests reveal a significant increase in the number of hours donated when recognition is promised in the low success condition $(F(1,71)=10.30, p$ $\left.<.01 ; \bar{X}_{\text {p recog }}=2.35>\bar{X}_{\text {no recog }}=1.21, \eta^{2}=.36\right)$ and no significant effect of promised recognition in the high success condition $\left(F(1,67)<1, p>.30 ; \bar{X}_{\mathrm{p} \mathrm{recog}}=1.06\right.$, $\left.\bar{X}_{\text {no recog }}=1.38, \eta^{2}=.12\right)$. As expected, we found no significant difference between the high and low success means in the no-recognition condition $(F(1,69)<1$, $p$ $\left.>.50 ; \bar{X}_{\text {low success }}=1.21, \bar{X}_{\text {high success }}=1.38, \eta^{2}=.07\right)$. We found that the number of hours volunteered was significantly different from zero only in the high group-need/ promised recognition cell $(p<.10)$. Interaction effect findings related to social approval and the number of hours donated are summarized in Table 1 and Figure 1.

Further insight into the results is provided by an analysis of the percentage of prospective volunteers who donated time in each of the four experimental conditions. The overall proportion of subjects who volunteered at least one hour of time was 59 percent. The highest proportion of volunteers was in the low group success/promised recognition cell with 81 percent of prospective volunteers donating time to the fund-raising team (see Table 1). A chi-square test revealed a significant difference in the proportion of subjects across the four conditions $\left(\chi^{2}\right.$ $=11.23, d f=3, p<.05)$. The results suggest that promised recognition increased the proportion of volunteers who would help within the low group success/high recognition cell.

Mediational Test. A series of regression analyses was undertaken to examine whether expectations of social approval mediate between the recognition by group success interaction and the number of hours donated. According to Baron and Kenny (1986), a test of mediation requires three regression equations: (1) a regression of social approval on the interaction term, (2) a regression of the number of hours donated on the interaction term, and (3) 
FIGURE 1

EFFECTS OF GROUP SUCCESS AND RECOGNITION ON SOCIAL APPROVAL AND HOURS DONATED: EXPERIMENT 1

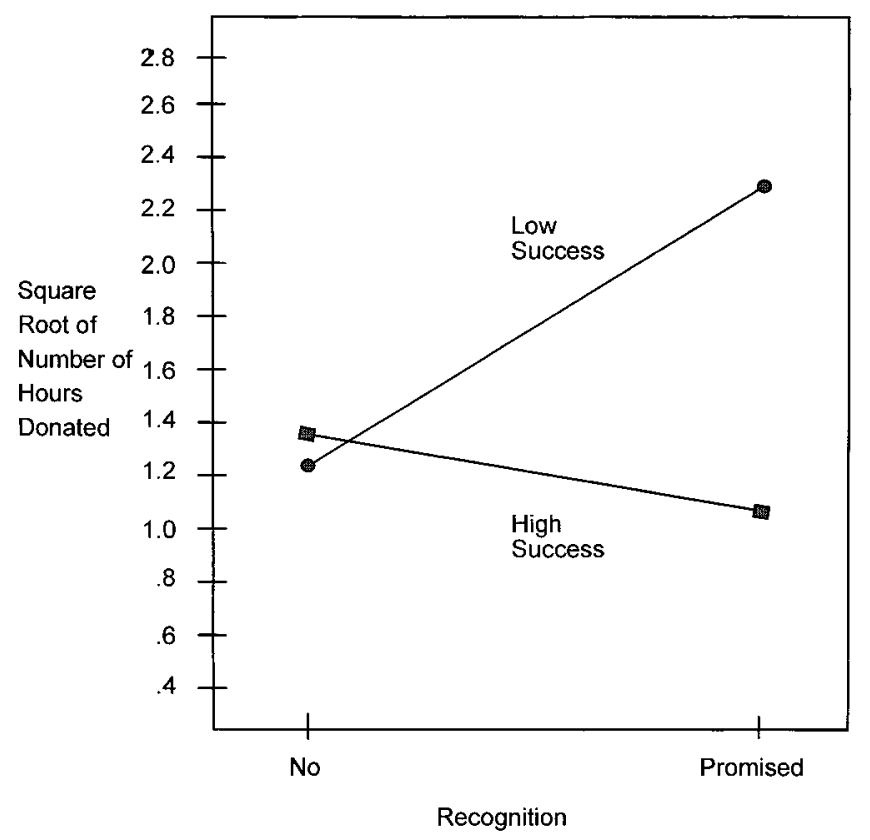

a regression of the number of hours donated on both the interaction term and social approval. If significant effects in the expected direction are found for equations (1) and (2), and the effect of social approval on the number of hours donated is significant in equation ( 3 ), then evidence of mediation exists. Because the interaction term includes both the main and interaction effects of its constituent elements, main effect terms were included in all three equations (see Cohen and Cohen 1983).

Results of the analysis are consistent with the anticipated mediational role of social approval. We found (1) a significant effect of the interaction term on social approval $(\beta=-.31, t=-2.17, p<.05) ;(2)$ a significant effect of the interaction term on the number of hours donated $(\beta=-.42, t=-3.04, p<.01)$; and (3) when both social approval and the interaction term are used to predict the number of hours donated, the effect of social approval is significant $(\beta=.28, t=3.44, p<.01)$. The results suggest that social approval is a mediator between the interaction term and the number of hours donated.

Ceiling Effect Test. A possible counterexplanation for the results is that a ceiling effect exists when success is high. This explanation assumes that under high success conditions individuals are already donating the maximum time they are willing or able to contribute. The addition of recognition or any other inducement under high group success would be ineffective as a consequence. However, the mean number of hours donated in the high success condition was below the middle of the range of zero to 25 hours donated, and there was no significant difference

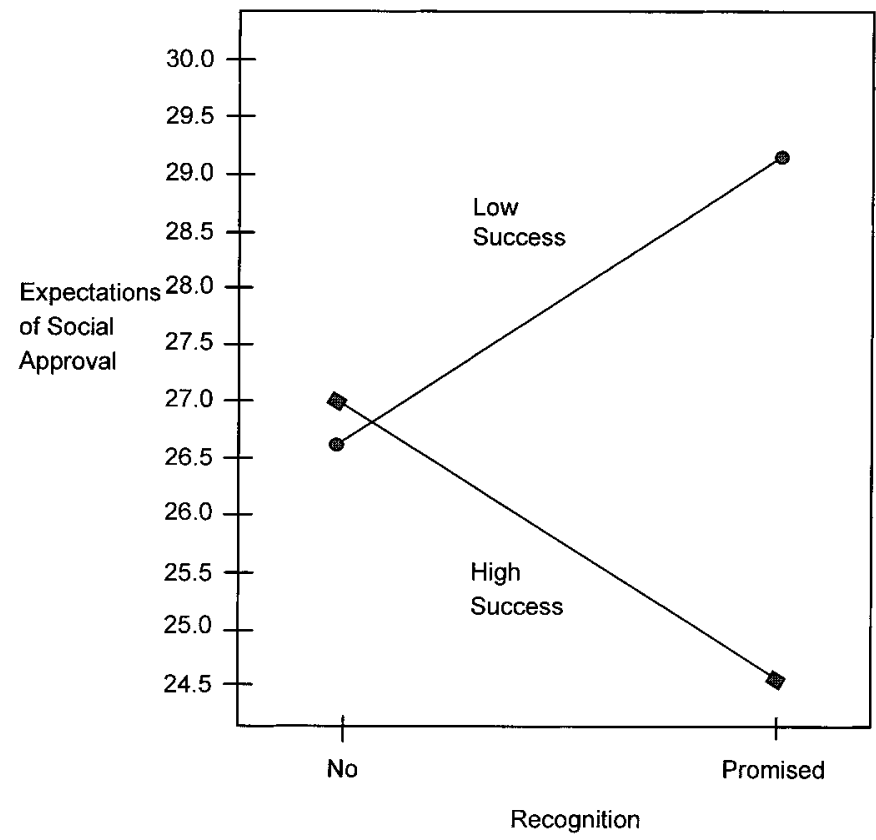

in the means in the low and high success conditions ( $F(1$, $139)=1.30, p>.20)$. Although not significant, the pattern of means is the opposite of what would be anticipated under a ceiling effect explanation with a higher mean in the low success condition $\left(\bar{X}_{\text {low success }}=10.24\right.$ hours, $\bar{X}_{\text {high success }}=7.94$ hours $)$. On this basis, the lack of a recognition effect under high success conditions cannot be attributed to a ceiling effect.

\section{Experiment 1 Discussion}

The results of experiment 1 are supportive of the study's main hypothesis with a significant group success by promised recognition interaction effect on the number of hours donated. A social norm perspective asserts that the manipulations jointly increased the number of hours donated by elevating the importance of volunteering and associating group-mediated rewards with the behavior. Mediational tests revealed that the manipulations heightened expectations of social approval that in turn lead to an increase in the number of hours donated. A normbased interpretation of the results is supported by the manipulations' effects on measures of group need and social approval, and the mediational findings related to social approval.

As hypothesized, we found that group success had a significant negative influence on evaluations of group need. Subjects who were given information that their school's fund-raising team had failed in each of the previous three years indicated that the group was in need of volunteer help. In contrast, subjects who were informed 
that the fund-raising team had been successful over the same period evaluated the team's need for volunteers to be relatively low. The results suggest that subjects used the team's recent performance as an indicator of group need and a measure of their own potential to contribute to the team's future success.

Also as hypothesized, promised recognition enhanced expectations of social approval only when group success was low. When group success was high, the predicted level of social approval was the same whether subjects thought they would receive an award from their dean at graduation or no recognition at all. The contingent nature of the recognition effect suggests that the social value of the award at graduation was a direct function of subjects' beliefs about the importance of their contribution to the fund-raising team. Put differently, recognition did not have intrinsic value in that its effects on social approval and the number of hours donated were contingent on the importance of the behavior being rewarded. Indeed, the promise of recognition caused a slight reduction in expectations of social approval in the high group success condition (although the difference between the high success/ no-recognition and high success/promised recognition means was not significant at $p<.05)$. Subjects may have felt ambivalent or even guilty about receiving recognition under high group success because they would be rewarded for making only a marginal contribution to the group.

Similarly, expectations of social approval from volunteering were the same whether subjects thought the fundraising team had won or lost for the previous three years. The lack of a main effect of group success is somewhat surprising given the typically strong relationship between undergraduate students and their university. Although subjects appeared to recognize the importance of helping when group success was low, they did not anticipate that others would be more supportive of volunteerism in the absence of a formal expression of appreciation by the school.

A similar pattern of effects occurred for the number of hours donated with no effect of recognition on contributions when group success was high and no effect of group success in the absence of recognition. Beyond the social norm perspective proposed here, it is reasonable to expect that helping their school win the fund-raising competition would make undergraduate students feel good for other (i.e., nonsocial) reasons. In particular, helping the unsuccessful fund-raising team "turn it around" might increase feelings of personal satisfaction or help the student avoid feelings of guilt. Similarly, receiving a volunteering award might be gratifying regardless of the reactions of others. Yet, neither low group success nor the promise of recognition alone was sufficient to motivate subjects to donate more time to the fund-raising cause.

\section{EXPERIMENT 2}

Experiment 2 was motivated by the desire to replicate the results of the first experiment in a field setting to evaluate the commitment of volunteers to follow through on their pledges. A second objective was to employ a more typical volunteering context than the student fundraising competition used in experiment 1. Experiment 2 was designed to be a noncompetitive context and one in which the group and its members were less formally linked. One consequence of this setting was that group need could be manipulated directly rather than indirectly through group success. Finally, a second experiment would allow us to include additional process and confound checks related to the effects of the recognition manipulation on the perceived visibility of volunteering, the distinctiveness of the recognition offered, and subjects' personal (i.e., nonsocial) feelings about helping. We discuss the rationale for each of these extensions in the next section.

\section{Method}

Experiment 2 employed a 2 (low/high group need ) $\times 2$ (no/promised recognition) design. Subjects were parents registering their children (four to 17 years of age) for the upcoming season of a youth soccer league. Researchers were given permission by league officials to run the experiment as part of their actual registration process with three provisions. First, the information given to subjects had to be truthful and so any promises of recognition would have to be fulfilled. Second, the manipulations could not contain information that was detrimental to the organization's image. Third, researchers were asked to make the experimental package as brief as possible to ensure that the registration process was not disrupted.

As subjects began the registration process they were given the research instrument and a flyer asking for volunteers to help at a yearly event called "Soccer Festival.", The manipulations of group need and recognition were contained in the flyer. Group need was manipulated with information about the level of volunteer help received at the prior year's event. Subjects in the low need condition were given information that "we had plenty of volunteers at last year's Soccer Festival, but we want your help too!', The high need condition flyers indicated that "we were very short of volunteers at last year's Soccer Festivalwe desperately need your help!'’

Recognition was manipulated with information about the extent to which volunteers could expect a public expression of gratitude from the organization. Subjects in the promised recognition condition were informed that they would receive an official 'I'm a Volunteer' T-shirt. The T-shirt would be worn by volunteers at the Soccer Festival because "we want everyone to know who our volunteers are and to recognize their good work!', 3 Sub-

\footnotetext{
${ }^{3}$ Based on a reviewer's concern, we ran a 2 (high/low need $) \times 2($ no/ private appreciation) between-subjects design as a separate part of the data collection effort $(n=88)$. All aspects of the study were the same as experiment 2 except that promised appreciation was manipulated with information on the flyer that stated, "We send volunteers a T-shirt to thank them for helping at Soccer Festival Day.' We do not report the results here because we found no significant appreciation main effect
} 
jects in the no-recognition condition did not receive any information about a formal acknowledgement by the league for their participation. Regardless of recognition condition, all volunteers who helped at Soccer Festival were given a free $\mathrm{T}$-shirt by the league (donated by the researchers ).

Subjects were randomly assigned to each of the four conditions (23-25 per cell) as they arrived at the registration location. Of 150 subjects handed an instrument and asked to "fill out a league survey on volunteering,", 97 indicated that they had read the flyer and completed all questions for a 65 percent response rate. The response rate did not differ across the four cells based on a chisquare test $(p>.20)$. Subjects tended to be female (64 percent) with an average age of 34 and with two or three children living at home.

\section{Measurement}

Manipulation Checks. The manipulation check for group need was the sum of "your help is important to this year's Soccer Festival" and "you are needed as a volunteer at this year's Soccer Festival', $(\bar{X}=11.22, r$ $=.73, \sigma=2.90)$. The manipulation check for recognition was the sum of "the organization properly thanks Soccer Festival Volunteers", and "the organization shows its gratitude to Soccer Festival Volunteers' ( $\bar{X}=10.62, r$ $=.95, \sigma=3.10)$. The measures were based on sevenpoint "strongly disagree" to "strongly agree" scales.

Perceived Social Visibility. We wanted to examine whether the recognition manipulation lead to heightened perceptions of social visibility for volunteers. Our measure of social visibility used the question stem, "The help of volunteers at this year's Soccer Festival will be ....", and asked subjects to respond on a seven-point semantic differential scale anchored with "not noticed" and "noticed" $(\bar{X}=5.94, \sigma=1.27)$.

Estimated Proportion of Volunteers. Given that recognition is valued more when it is distinctive, the pattern of results from the first experiment could be explained by the tendency of subjects in the low success/promised recognition cell to predict that relatively few people would volunteer to help. If this were the case, a confound would exist because it is unclear whether differences in the number of hours donated resulted from recognition's distinctiveness or its capacity to visibly reward an important behavior. We therefore asked subjects to predict the number of prospective volunteers who would help at Soccer Festival. The question was, "Out of 10 people asked to volunteer, approximately how many do you think actually will?', Subjects then circled a number between

or group need by appreciation interaction effect on (1) expectations of social approval or $(2)$ the number of hours donated $(p>.20)$. Thus, providing subjects with a free T-shirt (privately) did not have the same impact as a T-shirt that communicated the group's appreciation publicly. zero and 10, anchored with "no one who is asked will volunteer'" and "everyone who is asked will volunteer,' respectively $(\bar{X}=4.43, \sigma=2.15)$.

Personal Feelings. A measure of subjects' personal feelings about volunteering was included to capture the personal (i.e., nonsocial) effects of the manipulations. We anticipated that subjects would have more positive feelings when group need was high because it is in this condition that their contribution is most important to the group. We also wanted to evaluate the potential for recognition to have been effective in the high group-need condition for personal reasons. In particular, recognition might be valued as much as an expression of the group's appreciation as for its social effects. If this were the case, communicating the group's appreciation for helping in private might be as effective as a public award. Evidence of the nonsocial value of recognition would exist if we found that the group need by promised recognition interaction hypothesized for social approval also occurred for subjects' personal feelings about volunteering. We examined this potential by asking subjects how they would feel about volunteering at the Soccer Festival on a one to seven, "very bad" to "very good" scale $(\bar{X}=5.46$, $\sigma=1.49$ ).

Expectations of Social Approval. We used a two-item measure of social approval based on the anticipated reaction of other parents at the Soccer Festival and other volunteers. The question stem was, "Would people in each of these groups appreciate it if you volunteered to help on Soccer Festival Day?', A seven-point "very unlikely" to "very likely" scale was used $(\bar{X}=11.23, r$ $=.72, \sigma=2.49$ ).

Number of Hours Donated. The measure of the number of hours donated was, "How many hours would you be willing to volunteer for Soccer Festival, if any?' Subjects were asked to circle a number between zero and 11 or more hours $(\bar{X}=2.43, \sigma=1.78)$.

Volunteer Commitment. A potential weakness of any study based on self-reports is that subjects might not act in a way that is consistent with their stated intentions. The lack of correspondence between predicted and actual behaviors might be particularly acute for volunteering because participation is costly in terms of time and effort. Therefore, we asked subjects to include their name and phone number at the end of the questionnaire if they had indicated a willingness to help. Volunteers who included this information on the questionnaire could expect to be called by the organization to fulfill their pledge. This is the actual approach used by the soccer league to identify and ultimately contact volunteers.

\section{Results}

Manipulation Checks. An ANOVA revealed that perceptions of group need and promised recognition were manipulated as intended. The need manipulation had a 
TABLE 2

INTERACTION EFFECTS OF PROMISED RECOGNITION AND GROUP NEED ON SOCIAL APPROVAL AND VOLUNTEER PARTICIPATION: EXPERIMENT 2

\begin{tabular}{|c|c|c|c|c|}
\hline & \multicolumn{2}{|c|}{ High group need } & \multicolumn{2}{|c|}{ Low group need } \\
\hline & No recognition & $\begin{array}{l}\text { Promised } \\
\text { recognition }\end{array}$ & No recognition & $\begin{array}{l}\text { Promised } \\
\text { recognition }\end{array}$ \\
\hline Social approval & $\begin{array}{c}10.58 \\
(2.64)\end{array}$ & $\begin{array}{c}12.48 \\
(1.88)\end{array}$ & $\begin{array}{c}11.00 \\
(2.80)\end{array}$ & $\begin{array}{c}10.76 \\
(2.47)\end{array}$ \\
\hline Number of hours donated & $\begin{array}{c}2.33 \\
(1.93)\end{array}$ & $\begin{array}{c}3.56 \\
(1.48)\end{array}$ & $\begin{array}{c}1.96 \\
(1.85)\end{array}$ & $\begin{array}{l}1.76 \\
(1.36)\end{array}$ \\
\hline $\begin{array}{l}\text { Proportion of subjects volunteering } \\
\text { at least one hour (\%) }\end{array}$ & $\begin{array}{l}71 \\
24\end{array}$ & $\begin{array}{l}96 \\
25\end{array}$ & $\begin{array}{l}70 \\
23\end{array}$ & $\begin{array}{l}72 \\
25\end{array}$ \\
\hline
\end{tabular}

NOTE. - Values shown are means; standard deviations are shown in parentheses.

significant effect on perceived need $(F(1,96)=12.41$, $\left.p<.01, \bar{X}_{\text {high need }}=12.14>\bar{X}_{\text {low need }}=10.16, \eta^{2}=.34\right)$, and the recognition manipulation had a significant effect on perceived recognition $(F(1,96)=20.41, p<.001$, $\left.\bar{X}_{\text {p recog }}=11.88>\bar{X}_{\text {no recog }}=9.33, \eta^{2}=.42\right)$. No other significant main or interaction effects were found.

Perceived Social Visibility. As expected, we found a significant main effect of the recognition manipulation on subjects' perceptions of the visibility of volunteering $(F(1,96)=8.68, p<.01)$. Subjects in the promised recognition condition perceived that volunteering would be more visible than subjects in the no-recognition condition $\left(\bar{X}_{\text {p recog }}=6.28>\bar{X}_{\text {no recog }}=5.56, \eta^{2}=.29\right)$.

Estimated Proportion of Volunteers. We found no significant main or interaction effects of the manipulations on the proportion of people expected to volunteer ( $p$ $>.10)$. Consequently, the results cannot be explained by variations in the perceived distinctiveness of the recognition promised by the organization.

Personal Feelings. There was a significant main effect of group need on subjects' personal feelings about volunteering with more positive feelings when group need was high $\left(F(1,96)=6.40, p<.05, \bar{X}_{\text {high need }}=5.80\right.$ $\left.>\bar{X}_{\text {low need }}=5.06, \eta^{2}=.22\right)$. Promised recognition and group need did not interact to affect subjects' personal feelings about volunteering $(p>.20)$. These results suggest that the effect of the manipulations on the number of hours donated was not the result of differences in subjects' personal feelings about volunteering.

Expectations of Social Approval. We found a significant interaction of promised recognition and group need on social approval $(F(1,96)=4.76, p<.05)$ with the pattern of means consistent with the hypothesis. A simple effects test reveals that the mean social approval level was significantly higher when recognition was promised under high group need $\left(F(1,48)=9.32, p<.01, \bar{X}_{\mathrm{p}}\right.$ recog $\left.=12.48>\bar{X}_{\text {no recog }}=10.58, \eta^{2}=.41\right)$ but not under low group need $\left(F(1,47)<1, p>.70, \bar{X}_{\text {precog }}=10.76\right.$, $\left.\bar{X}_{\text {no recog }}=11.00, \eta^{2}=.08\right)$. As expected, there was no significant difference between the high and low need means in the no-recognition condition $(F(1,46)<1, p$ $\left.>.60 ; \bar{X}_{\text {high need }}=10.58, \bar{X}_{\text {low need }}=11.00, \eta^{2}=.08\right)$. The effects of group need and recognition on social approval are consistent with the hypothesis. No main effect of either manipulation was found on expectations of social approval.

Number of Hours Donated. The subject population had the potential to volunteer for several tasks in addition to the Soccer Festival. We therefore included the number of other tasks the subject volunteered for as a covariate to the number of hours donated at Soccer Festival. We found a significant interaction between promised recognition and group need $(F(1,96)=5.55, p<.025)$ with the number of other positions volunteered for by the subject a significant covariate $(F(1,96)=11.21, p<.01)$. Simple effects tests reveal a significant increase in the self-reported number of hours donated when recognition is provided in the high need condition $(F(1,48)=6.30, p$ $\left.<.025 ; \bar{X}_{\text {p recog }}=3.56>\bar{X}_{\text {no recog }}=2.33, \eta^{2}=.34\right)$ and no significant difference in the low need condition $(F(1$, $47)<1, p>.50 ; \bar{X}_{\text {p recog }}=1.76, \bar{X}_{\text {no recog }}=1.96, \eta^{2}$ $=.09)$. As expected, there was no significant difference between the high and low group need means when recognition was not offered $(F(1,46)<1, p>.60$; $\left.\bar{X}_{\text {high need }}=2.33, \bar{X}_{\text {low need }}=1.96, \eta^{2}=.08\right)$. Consistent with experiment 1 , we found that the number of hours volunteered was significantly different from zero only in the high group-need/promised recognition cell $(p<.05)$.

We examined the overall proportion of subjects who volunteered at least one hour of time and found that 77 percent of subjects stated a willingness to participate. A chi-square test reveals a significant difference in the proportion of subjects who volunteered across the four cells $\left(\chi^{2}=8.58, d f=3, p<.05\right)$ with 96 percent of subjects volunteering in the high group-need/promised recognition cell. The results are consistent with experiment 1 and 
FIGURE 2

EFFECTS OF GROUP NEED AND RECOGNITION ON SOCIAL APPROVAL AND HOURS DONATED: EXPERIMENT 2

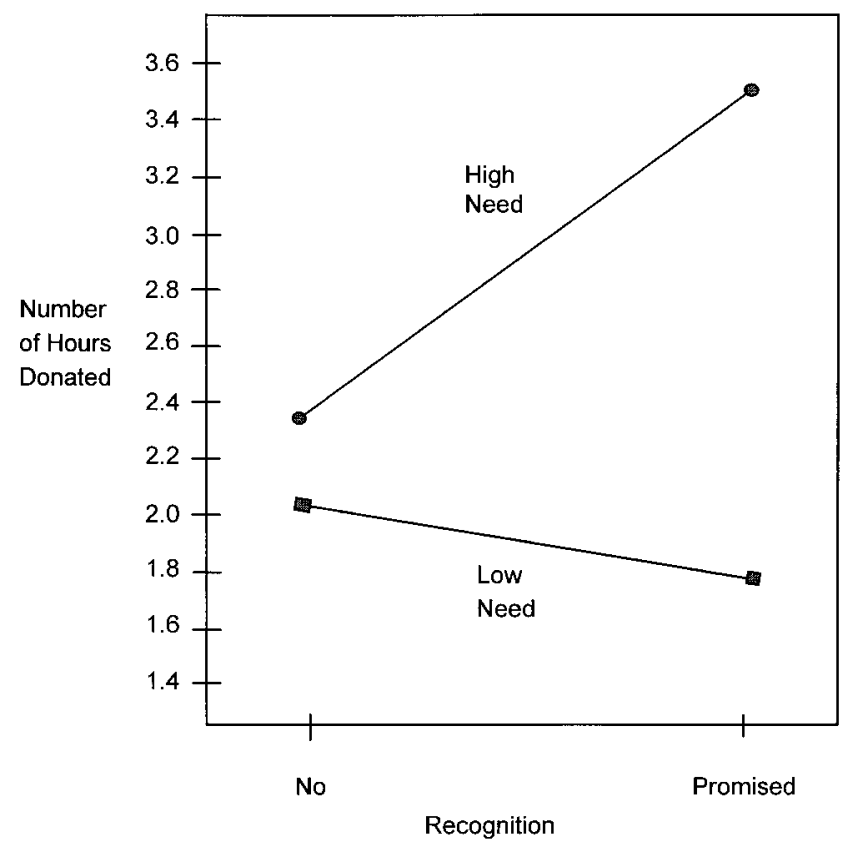

illustrate how the interaction of the manipulations affected the willingness of prospective volunteers to participate. The results related to the interaction effects are summarized in Table 2 and Figure 2.

Mediational Tests. As in experiment 1 we used path analysis to examine the mediational hypothesis. Using the same series of equations outlined in the first study we found results that are consistent with a mediational role of social approval. We found (1) a significant effect of the interaction term on social approval $(\beta=.38, t=2.18$, $p<.05)$, (2) a significant effect of the interaction term on the number of hours donated $(\beta=.33, t=1.97$, $p<.05)$, and (3) when both social approval and the interaction term are used to predict the number of hours donated, the effect of social approval is significant at $p$ $<.10(\beta=.15, t=1.48) .{ }^{4}$ Further, we combined across the two experiments to summarize the results (see Rosenthal and Rubin 1986). We found a highly significant effect of social approval on the number of hours donated given the effects of recognition and group need $(Z=$ $4.67, p<.01)$. The strength and consistency of the result across experiments provides further evidence of the mediating role of social approval.

Ceiling Effect Test. The mean number of hours donated in the low need condition was below the middle of

\footnotetext{
${ }^{4}$ As noted by Baron and Kenny (1986) the use of regression analysis tends to understate the effect of the mediator and overstate the effect of the independent variable because of measurement error.
}

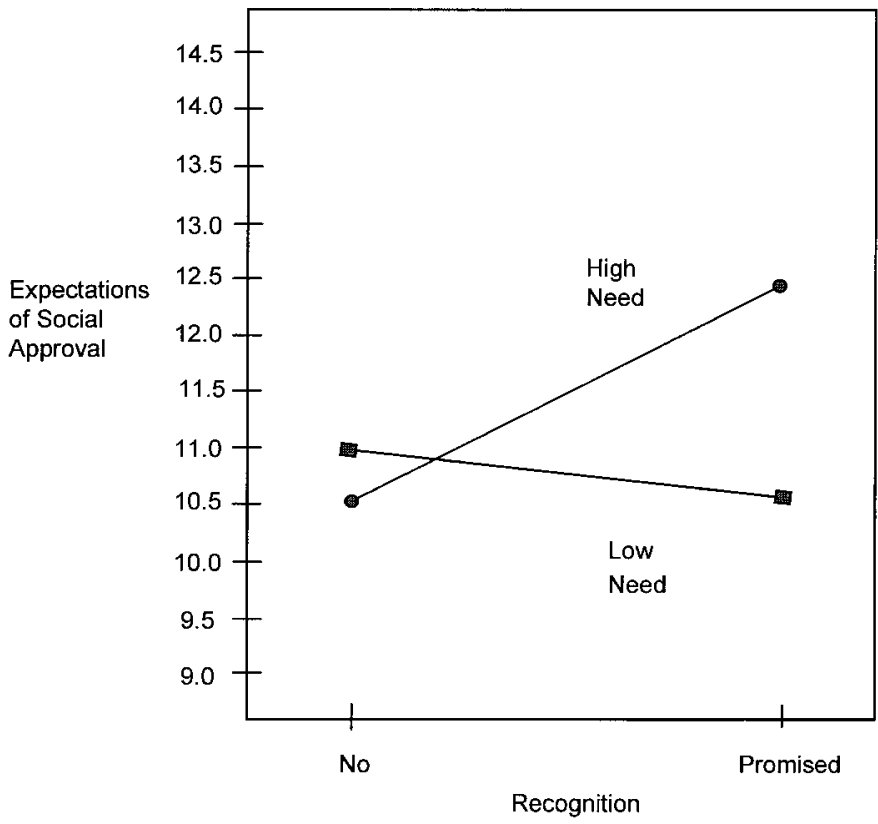

the range of zero to 11 or more hours donated and the mean in the high need condition was larger than the mean in the low need condition $\left(\bar{X}_{\text {high need }}=2.96>\bar{X}_{\text {low need }}\right.$ $=1.90)$. Consequently, the lack of a recognition effect in the low need condition cannot be attributed to a ceiling effect (i.e., that subjects were already donating the maximum time they are willing or able to contribute in the low need condition).

Volunteer Commitment. Seventy-three percent of those who volunteer at least one hour to the Soccer Festival included their name and phone number on the questionnaire. Commitment was strongest in the high groupneed/promised recognition cell with 80 percent including the information needed to contact them, although there was no significant difference across cells $(p>.30)$. These results provide some confidence that the self-report data we collected would translate into actual differences in volunteering behaviors.

\section{Experiment 2 Discussion}

The purpose of experiment 2 was to replicate the results of the first study in a field setting and to provide further insights into the social norm hypothesis. In terms of the replication objective, both experiments found that promised recognition increased expectations of social approval and the number of hours donated only when group need was high. Both experiments also found support for the role of social approval as a mediator between the interaction term and the number of hours volunteered. Finally, 
neither experiment found a significant difference for either social approval or the number of hours donated between (1) the no- and promised-recognition cells when group need was low, or (2) the high and low group-need cells when recognition was not promised.

Experiment 2 also addressed the potential confound that promised recognition affected the number of hours donated because of variations in its perceived distinctiveness rather than its greater value when group need is high. The results revealed that the manipulations had no significant effect on subjects' predictions about the proportion of others who would help. We found no evidence that recognition's perceived distinctiveness varied across conditions.

Experiment 2 provided further insights into how recognition affects the willingness to volunteer. As expected, we found that the promise of recognition elevated subjects' predictions about the visibility of volunteering. We also found that subjects felt more positive about volunteering when group need was high, but this did not translate into a main effect of group need on the number of hours donated. Finally, there was no interaction effect of group need and recognition on personal feelings about volunteering. These results, coupled with the interaction of the manipulations with respect to both social approval and number of hours donated, indicate that recognition was more effective under high group-need conditions for social rather than personal reasons. Moreover, and consistent with experiment 1 , it appears that recognition did not have intrinsic value to subjects. It was only when subjects thought that their contribution was important and therefore more socially desirable that recognition increased the number of hours donated.

Experiment 2 included a measure of volunteer commitment to examine the effects of the manipulations on actual behaviors. The vast majority of subjects who volunteered were willing to provide their name and telephone number so that the organization could contact them later about their offer to help. No significant difference was found across cells in the willingness of subjects to provide this information. Written commitments such as the one used in experiment 2 have been found to be highly correlated with behaviors across a variety of settings (for a review of this evidence see Cialdini [1993]).

An examination of cell means revealed that only the number of hours donated in the high need/promised recognition cell is significantly different from zero. By implication, a statistically meaningful level of volunteering occurred only when the behavior was important to the group and a group-mediated reward was expected for helping. The results do not, however, suggest that subjects only volunteered for selfish reasons such as increased social approval. The majority of subjects in both experiments volunteered to help even when group need was low and no recognition was promised. In other words, most subjects responded to a request for help without any inducement whatsoever.

\section{GENERAL DISCUSSION}

Beyond the robust nature of the results across experimental settings and samples, several differences between the two experiments are worthy of discussion. The first difference is that the volunteering behaviors we studied in experiment 1 were clerical tasks that were not highly visible to others in the group (i.e., stuffing envelopes, making copies, etc.) whereas in experiment 2 the tasks were much more visible (i.e., working in a snack booth serving other parents and volunteers). One might expect that recognition would be less important for the socially visible tasks in experiment 2 because others would already notice and have the ability to reinforce the behaviors. However, this was not the case as recognition was also effective in experiment 2.

The studies also differed in the extent to which prospective volunteers were associated with the group seeking help. In experiment 1 subjects were asked to volunteer to a fund-raising group that was a subunit of their business school. In this instance subjects had an established relationship with the group seeking help. In contrast, subjects in experiment 2 were in the process of registering their children for a youth soccer league. The parents' connection to the soccer league is typically informal and limited. The differing levels of group connection across studies did not affect the pattern of results although the average number of hours volunteered by students was much higher ( $\bar{X}_{\text {Exp } 1}=4.5$ hours, $\bar{X}_{\text {Exp } 2}=2.4$ hours $)$.

Finally, the studies differed with respect to the nature of the manipulations. In experiment 1 the volunteer-based group was competitive, and so perceptions of group need were influenced by information about the group's performance relative to a "hated" crosstown rival. In contrast, the group-need manipulation in experiment 2 was based directly on the organization's level of volunteer support. In terms of the recognition manipulations, subjects in the promised recognition condition in experiment 1 were told they would receive a plaque at their graduation ceremony whereas in experiment 2 subjects were informed they would receive an official volunteer T-shirt in appreciation for helping. The differences in the manipulations were necessary to examine the hypotheses in the varied group contexts, but they did not affect the pattern of results.

\section{Directions for Future Research}

Future research is needed to understand the effects of group success and recognition on factors related to volunteer loyalty, task performance, and task-related satisfaction. Recognition could have a significant effect on longterm aspects of volunteering related to retaining existing volunteers and maintaining their participation levels. Examining this phenomenon would require a research design very different from that used in the present studies. Specifically, the research would need to examine attitudes and behaviors subsequent to both volunteer participation and the presence or absence of actual recognition. 
Also related to the temporal aspects of the study is the potential for low success or high need appeals to be less effective with repeated use. One reason for diminishing returns and perhaps even a negative effect on volunteering is that "cries of wolf" ' become less believable the more they are employed. A second reason is that the target might become more likely to assume that the reason for low success (or high need) lies within the group rather than outside it ( see Folkes 1988). Consequently, prospective volunteers might be less likely to contribute time and effort to a group that is seen as responsible for its own lack of success. Other evidence suggests that the use of extrinsic rewards will lessen the intrinsic satisfaction of volunteering and weaken task performance (for a review see Lepper and Greene [1978]).

Future research also might benefit from applying the social norm concepts examined here to other socially desirable consumption behaviors such as litter reduction, blood donation, energy conservation, and recycling. Given that the likelihood of undertaking such behaviors is elevated when they are perceived to be both highly desirable and socially visible, organizations can undertake strategies to encourage the behaviors. For example, recycling might be increased by a combination of advertising that highlights the importance of the behavior and the use of highly visible recycling bins and containers. Petroleum companies could promote the purchase of cleaner gasolines by emphasizing the country's need to reduce auto emissions and offering bumper stickers that identify the driver as "part of the solution." The Red Cross might benefit from developing closer ties between promotional campaigns that highlight blood supply shortages and the provision of pins that identify people who have given blood that day. Social norm concepts might be usefully applied to the promotion of other socially desirable behaviors as well.

\section{Conclusion}

The article reports on two experiments that found a significant interaction between group need and the value of recognition. Experiment 1 was a laboratory study using student subjects in a competitive group setting. Experiment 2 was a field study using nonstudent subjects in a cooperative setting. Both experiments found that promised recognition increased volunteer participation only when the group seeking support was portrayed as needy. No other effects of group need or promised recognition on the extent of volunteering were found. The results suggest that volunteer organizations must be sensitive to the context under which they establish recognition programs and use promotional appeals based on the significance of their need.

[Received June 1996. Revised May 1998. Brian Sternthal and Robert E. Burnkrant served as editors, and Joseph W. Alba and Richard F. Yalch served as associate editors for this article.]

\section{REFERENCES}

American Red Cross (1988), Volunteer 2000 Study: Findings and Recommendations, Vol. 1, Washington, DC: American Red Cross.

Babchuk, Nicholas and C. Wayne Gordon (1962), The Voluntary Association in the Slum, University of Nebraska Studies, New Series, No. 27, Lincoln: University of Nebraska Press.

Bagozzi, Richard P. (1981), “Attitude, Intentions and Behavior: A Test of Some Key Hypotheses,'” Journal of Personality and Social Psychology, 41 (October), 607-627.

(1982), "A Field Investigation of Causal Relations among Cognitions, Affect, Intentions, and Behavior, Journal of Marketing Research, 19 (November), 562-583.

_ and David J. Moore (1994), "Public Service Advertisements: Emotions and Empathy Guide Prosocial Behavior,' Journal of Marketing, 58 (January), 56-70.

Bandura, A. (1977), Social Learning Theory, Englewood Cliffs, NJ: Prentice-Hall

Baron, Reuben M. and David A. Kenny (1986), “The Moderator-Mediator Variable Distinction in Social Psychological Research: Conceptual, Strategic, and Statistical Considerations,' Journal of Personality and Social Psychology, 51 (December), 1173-1182.

Baron, Robert S., Norbert L. Kerr, and Norman Miller (1992), Group Processes, Group Decision, Group Action, Pacific Grove, CA: Brooks/Cole.

Batson, C. Daniel (1990) "How Social Is the Animal? The Human Capacity for Caring,' American Psychologist, 45 (March), 336-346.

Baumann, Donald J., Robert B. Cialdini, and Douglas T. Kendrick (1981), "Altruism as Hedonism: Helping and SelfGratification as Equivalent Responses,' Journal of Personality and Social Psychology, 40 (June), 1039-1046.

Belk, Russel W. (1995), "Awards, Rewards, Prizes, and Punishments,' in Advances in Consumer Research, Vol. 22, ed. Frank R. Kardes and Mita Sujan, Provo, UT: Association for Consumer Research, 9-15.

Bendapudi, Neeli, Surendra N. Singh, and Venkat Bendapudi (1996), "Enhancing Helping Behavior: An Integrative Framework for Promotion Planning,' Journal of Marketing, 60 (July), 33-49.

Berkowitz, Leonard and Larry R. Daniels (1964), "Affecting the Salience of the Social Responsibility Norm," Journal of Abnormal and Social Psychology, 68 (March), 275281.

Bonjean, Charles M., William T. Markham, and Patrick O. Macken (1994), "Measuring Self-Expression in Volunteer Organizations: A Theory-Based Questionnaire," Journal of Applied Behavior Science, 30 (December), 487-515.

Brakeley, George A. (1980), Tested Ways to Successful Fund Raising, New York: AMACOM.

Burnett, John J. (1981), "Psychographic and Demographic Characteristics of Blood Donors,' Journal of Consumer Research, 8 (June), 62-67.

Burnkrant, Robert E. and Thomas Page, Jr. (1982), “'An Examination of the Convergent, Discriminant, and Predictive Validity of Fishbein's Behavioral Intention Model,' Journal of Marketing Research, 19 (November), 550-561.

Carlo, Gustavo, Nancy Eisenberg, Debra Troyer, Galen Switzer, and Anna L. Speer (1991), "The Altruistic Personality: In What Contexts Is It Apparent,' Journal of Personality and Social Psychology, 61 (September), 450-458. 
Cialdini, Robert B. (1993), Influence: Science and Practice, 3d ed., New York: HarperCollins.

, Carl A. Kallgren, and Raymond R. Reno (1991), “A Focus Theory of Normative Conduct: A Theoretical Refinement and Reevaluation of the Role of Norms in Human Behavior,' in Advances in Experimental Social Psychology, Vol. 24, ed. Leonard Berkowitz, New York: Academic Press, 201-214.

— Mark Schaller, Donald Houlihan, Kevin Arps, Jim Fultz, and Arthur L. Beaman (1987), "Empathy-Based Helping: Is It Selflessly of Selfishly Motivated?' Journal of Personality and Social Psychology, 52 (April), 749758.

Cohen, Jacob and Patricia Cohen (1983), Applied Multiple Regression/Correlation Analysis for the Behavioral Sciences, Hillsdale, NJ: Erlbaum.

Dawson, Scott (1988), "Four Motivations for Charitable Giving: Implications for Marketing Strategy to Attract Monetary Donations for Medical Research," Journal of Health Care Marketing, 8 (June), 31-37.

DeRidder, Richard, Sandra G. L. Schruijer, and Rama C. Tripathi (1992), "Norm Violation as a Precipitating Factor in Negative Intergroup Relations," in Norm Violations in Intergroup Relations, ed. Richard DeRidder and Rama C. Tripathi, Oxford: Clarendon.

Eisenberg, Nancy (1982), The Development of Prosocial Behavior, New York: Academic Press.

Feldman, Daniel C. (1984), "The Development and Enforcement of Group Norms,' Academy of Management Review, 9 (January), 47-53.

Festinger, Leon, Stanley Schachter, and Kurt Back (1950), Social Pressures in Informal Groups, New York: Harper.

Fisher, Robert J. (1993), "'Socially Desirable Responding and the Validity of Indirect Questioning,' Journal of Consumer Research, 20 (September), 303-315.

Folkes, Valerie S. (1988), "Recent Attribution Research in Consumer Behavior: A Review and New Directions,", Journal of Consumer Research, 14 (March), 548-565.

Fraser, Cynthia, Robert E. Hite, and Paul L. Sauer (1988), "Increasing Contributions in Solicitation Campaigns: The Use of Large and Small Anchorpoints,' Journal of Consumer Research, 15 (September), 284-287.

Gallup Organization (1987), The Gallup Study of Public Awareness and Involvement with Non-Profit Organizations, Princeton, NJ: Gallup.

Gouldner, Alvin W. (1960), “The Norm of Reciprocity: A Preliminary Statement," American Sociological Review, 25 (April), 161-178.

Harrison, David A. (1995), "'Volunteer Motivation and Attendance Decisions: Competitive Theory Testing in Multiple Samples from a Homeless Shelter,' Journal of Applied Psychology, 80 (June), 371-385.

Hawes, Douglass K. (1977), "Time Budgets and Consumer Leisure-Time Behavior,' in Advances in Consumer Research, Vol. 4, ed. William D. Perreault, Jr., Atlanta: Association for Consumer Research, 221-229.

Henderson, Karla A. (1981), "Motivations and Perceptions of Volunteerism as a Leisure Activity," Journal of Leisure Research, 13 (3d Quarter), 208-218.

Holbrook, Morris B. and Donald R. Lehmann (1981), “Allocating Discretionary Time: Complementarity among Activities," Journal of Consumer Research, 7 (March), $395-$ 406.
Independent Sector, (1992) Caring and Giving in the United States: Findings from a National Survey, Washington, DC: Independent Sector.

Jenner, Jessica R. (1981), "Volunteerism as an Aspect of Women's Work Lives,' Journal of Vocational Behavior, 19 (December), 302-314.

Kotler, Philip (1982), Marketing for Nonprofit Organizations, Englewood Cliffs, NJ: Prentice-Hall.

LaTour, Stephen A. and Ajay Manrai (1989), "'Interactive Impact of Informational and Normative Influence on Donations,' Journal of Marketing Research, 26 (August), 327 335.

Leary, Mark R. (1995), Self-Presentation: Impression Management and Interpersonal Behavior, Boulder, CO: Westview.

Leibert, Edwin R. and Bernice E. Sheldon (1972), Handbook of Special Events for Nonprofit Organizations, New York: Association Press.

Lepper, Mark R. and David Greene (1978), The Hidden Cost of Reward: New Perspectives on the Psychology of Human Motivation, New York: Erlbaum.

Maxwell, Scott E. and Harold D. Delaney (1990), Designing Experiments and Analyzing Data, Belmont, CA: Wadsworth.

McGee, Lynne F. (1988), "Keeping Up the Good Work," Personnel Administrator, 33 (June), 68-72.

Meyers-Levy, Joan and Durairaj Maheswaran (1992), "'When Timing Matters: The Influence of Temporal Distance on Consumers' Affective and Persuasive Responses,' Journal of Consumer Research, 19 (December ), 424-433.

Moore, Ellen M., William O. Bearden, and Jesse E. Teel (1985), "Use of Labelling and Assertions of Dependency in Appeals for Consumer Support,' Journal of Consumer Research, 12 (June), 90-96.

Omoto, Allen M. and Mark Snyder (1995), “'Sustained Helping without Obligation: Motivation, Longevity of Service, and Perceived Attitude Change among AIDS Volunteers,', Journal of Personality and Social Psychology, 68 (April), 671-686.

Pearce, Jone L. (1993), Volunteers: The Organizational Behavior of Unpaid Workers, New York: Routledge.

Pessemier, Edgar A., Albert C. Bemmaor, and Dominque M. Hanssens (1977), "Willingness to Supply Human Body Parts: Some Empirical Results,' Journal of Consumer Research, 4 (December), 131-140.

Reingen, Peter H. (1978), " 'On Inducing Compliance with Requests,' Journal of Consumer Research, 5 (September), 96-102.

Reno, Raymond R., Robert B. Cialdini, and Carl A. Kallgren (1993), “The Transsituational Influence of Norms,' Journal of Personality and Social Psychology, 64 (January), 104-112.

Rosenthal, Robert and Donald B. Rubin (1986), "'Meta-Analytic Procedures for Combining Studies with Multiple Effect Sizes,' Psychological Bulletin, 99 (May), 400406.

Samuelson, Robert J. (1989), "Rediscovering the Rat Race," Newsweek (May 15), p. 57.

Schram, Vicki R. and Marilyn M. Dunsing (1981), "'Influences on Married Women's Volunteer Work Participation,' Journal of Consumer Research, 7 (March), 372-379.

Schwartz, Shalom H. (1977), "Normative Influences on Altru- 
ism," in Advances in Experimental Social Psychology, Vol. 10, ed. Leonard Berkowitz, New York: Academic Press, 221-279.

Smith, David Horton (1981), “Altruism, Volunteers and Volunteerism,' Journal of Voluntary Action Research, 10 (January-March), 21-36.

Tajfel, Henry (1970), "Experiments in Intergroup Discrimination," Scientific American, 223 (May), 96-102.
Turner, Bryan S. (1988), Status, Minneapolis: University of Minnesota Press.

Unger, Lynette S. (1991 ), "Altruism as a Motivation to Volunteer," Journal of Economic Psychology, 12 (March), 71-100.

Wilcox, Rand R. (1993), 'Robustness in ANOVA,' in Applied Analysis of Variance in Behavioral Science, ed. L. K. Edwards, New York: Marcel Dekker, 345374. 